ojs.uv.es/index.php/qdfed

Rebut: 02.06.2020. Acceptat: 20.07.2020

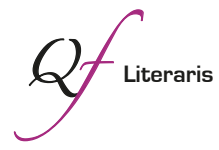

Per a citar aquest article: Valls Boix, Juan Evaristo. 2020. "De la gran huelga literaria. Jacques Derrida y los desvíos del performativo". Quaderns de Filologia: Estudis Literaris XXV: I87-205.

doi: $10.7203 /$ qdfed.25.19003

\title{
De la gran huelga literaria. Jacques Derrida y los desvíos del performativo
}

\author{
On the Great Literary Strike. Jacques Derrida and the Deviations of Performativity
}

Juan Evaristo Valls Boix

Universitat de Barcelona

valls-boix.j.e@ub.edu

Resumen: El propósito del siguiente estudio consiste en analizar la performatividad de la literatura en el pensamiento de Derrida y su potencial político para interrumpir procesos de constitución de órdenes simbólicos (identidades, razas, géneros). La capacidad de la literatura para "sabotear" la producción naturalizada de un orden a través de la operatividad del discurso radica en la particularidad de su fuerza performativa, que Derrida calificó en Force de loi como "fuerza de ruptura", o como el derecho a la huelga en toda interpretación. En este sentido, la performatividad de la literatura no consiste tanto en constituir como en destituir; no se trata tanto de colmar, como de holgar; no intenta producir o poner un mundo, sino deponerlo. Esta reflexión sobre la fuerza desviada o destituyente de la literatura mostrará su carácter político, así como de su estrecha vinculación con la democracia: la apertura u hospitalidad que exigen ambas es una permanente posibilidad de sabotaje y desinterpelación.

Palabras clave: Derrida; performatividad; literatura; huelga; sabotaje.

Abstract: The aim of this study is to analyze the performativity of literature in Derrida's thought, as well as its political possibilities to interrupt the constitution of symbolic orders (identities, races, genders). The capability of literature to "sabotage" the naturalized production of an order through the operativity of the discourse resides in the particularity of its performative force, which Derrida names in Force de loi as "force de rupture", or the right to strike in every interpretation. In this sense, the performativity of literature is not about constituting, but destituting; it is not about producing or positing the world, but deposing it. This study about the oblique force of literature will show its political character, as well as its tight link with democracy: the opening or the hospitality that both literature and democracy demand is a permanent possibility of sabotage and dis-interpellation.

Keywords: Derrida; performativity; literature; strike; sabotage. 


\section{Introducción}

Las más de las veces, defender esa extraña institución que es la literatura supone reconocer todo lo que nos da y todo lo que hace. Sea porque la ficción tiene el potencial performativo de crear mundos, sea porque ofrece formas de conocimiento inhallables en las regiones discursivas de la ciencia, o sea, en fin, porque brinda la oportunidad de dar voz a subjetividades subalternas. Sin embargo, toda una tendencia crítica de pensamiento en torno a la literatura como institución se ha afanado en vindicar su dimensión política no por lo que hace, sino por lo que deshace; no por lo que es, sino por lo que permite dejar de ser; en fin, no por lo que nos ofrece saber, sino por su resistencia a asumir cualquier certeza. Fueron Blanchot y Foucault quienes inauguraron esta línea de pensamiento al concebir la literatura como un afuera radical del discurso (cf. Foucault, 2009: 302-303). En línea con las anteriores, la desterritorialización de Deleuze y Guattari, la inoperancia de Agamben o el disenso de Rancière constituyen diversas propuestas contemporáneas de pensar la dimensión política de la literatura por su potencial de subversión discursiva, y no por su productividad.

El propósito del presente estudio consistirá en valorar la aportación que Jacques Derrida brindó en los años noventa a esta genealogía de la demolición literaria. La razón que vuelve pertinente revisar los planteamientos de Derrida es la contaminación que experimenta su trabajo de las problemáticas de la speech act theory desde los setenta en adelante, en que es la performatividad, y con ella la cuestión de la fuerza y la violencia, lo que estará en crisis en los frágiles límites de la institución literaria. No es tanto la literatura un espacio de afuera en Derrida, sino más bien un lugar en que las palabras dejan de hacer cosas para mostrar los nexos y las convenciones que han sostenido el vínculo entre la violencia y el lenguaje. De ahí que no sea preciso una crítica que venga a deconstruir un texto, o a sabotear sus vehiculaciones discursivas para abrir en él lecturas alternativas. Antes bien, es el "devenir-literatura" de todo texto, como Derrida indicó en Parages (2003a: 263) o en Dar la muerte (2006: I23), lo que trae en él una fuerza que resiste a cerrar su lectura en un único sentido. El devenir-literario de un texto constituye un índice de perversión de esa performatividad que le permitía sostener un orden simbólico, para así deponer en el texto cualquier orden, cualquier tesis. Siendo la literatura una "experiencia no-tética de la tesis" (Derrida, 20I7a: I25-I26), si hay performatividad en el texto, esta es la de una gran huelga literaria: una enmienda a la totalidad, una contestación radical de las leyes, los supuestos y las prácticas 
que articulan los modos habituales (académicos, policiales, editoriales, comerciales) de lectura y escritura. La performatividad de la literatura no consiste tanto en constituir, como en destituir; no se trata tanto de colmar, como de holgar. Esta reflexión sobre la fuerza desviada o destituyente de la literatura dará cuenta de su carácter político, así como de su estrecha vinculación con la democracia: la apertura u hospitalidad que exigen ambas es una permanente posibilidad de sabotaje y desinterpelación.

Expuesta esta introducción, procederemos como sigue: ofreceremos un análisis general sobre la concepción de Derrida de la literatura como institución (I), para considerar después (2) la dimensión performativa de la literatura a través de la noción de "fuerza débil". Continuaremos (3) para valorar esta fuerza a través del personaje de Bartleby. Finalmente (4), valoraremos algunas tendencias contemporáneas que han continuado pensando esta performatividad destituyente de la literatura a través de fenómenos textuales como el grito (Cixous), la huelga (Hamacher) y la queja (Ronell). Estas valoraciones consolidarán los diagnósticos de Derrida para pensar una performatividad literaria que preferiría no hacer ni decir, y es esta suspensión lo que abre en el espacio literario la oportunidad para la experiencia o el acontecimiento.

\section{La institución de la literatura}

Dediquemos un momento a revisar el modo en que Derrida concibe esa institución que solemos llamar literatura. Lejos de constituirse como ese afuera o esa "blancura esencial" que Foucault ensayara (2015: 38), la literatura para Derrida es un espacio enteramente convencional, sujeto a un marco legal que determina en cada momento qué se considera y qué no literatura. Lo literario, pues, no consiste en ningún rasgo textual o semántico, y no tiene ninguna autonomía. Ninguna ley propia de la literatura: nada más, para definir la literatura, que una heteronomía, la fuerza-de-ley convencional de academias, instituciones, editoriales: la literatura, pues, "n'a d'existence et de consistance qu'aux conditions de la loi”, valora Derrida en "Préjugés" (I985: I33). Así, ningún carácter mayestático o soberano para la literatura: toda la potencia de la literatura va ligada a una impotencia, la incapacidad de constituirse a sí misma como discurso o institución.

Su carácter estrictamente convencional implica, por ello, que la literatura comparte las condiciones de posibilidad de la ley (I985: I09): nace la literatura en un cierto momento de la historia del derecho, que es el del surgimiento 
de la figura jurídica moderna de autor, según observa Derrida en su seminario "Répondre - du secret" (I99I-92): cuando nace la literatura, lo hace acogida por su padre, con un autor que la sostiene bajo la estructura y la metáfora de la paternidad. Y por ello, como institución, lo literario es meramente una cuestión de derecho, es dependiente de todo aquello que sí tiene una ley propia. Solo esa fuerza-de-ley exterior va a garantizar que la literatura abra algo así como una fuerza-sin-ley, un hiato entre texto y discurso, una inesencialidad que es tanto la singularidad como la banalidad del texto literario. Solo una ley que limite la literatura como falta-de-límite la dotará de la consistencia de la que esta carece. Así, la literatura es una institución que desborda la institución (Derrida y Attridge, 2009: 256), cuestiona la estructura misma de la institución, el vínculo entre texto y fuerza que permite delimitar un orden institucional. La literatura se caracteriza por una indeterminación fundamental de estatuto que solo gracias a un estatuto legal puede desplegarse. Solo gracias a esa fuerza, la literatura puede desplegar una dinámica paradójica según la que, al desprenderse de todas sus propiedades (su origen, su contexto de emisión, el querer-decir de su autor, su mensaje, su público), no deja de "ser" literaria, sino que lo "es" más que nunca, en virtud del "no ser" que le permite cultivar la fuerza legal que la sostiene. Gracias a ello, la literatura ofrece un acceso privilegiado a la «estructura general de la textualidad» (Derrida y Attridge, 2009: 289) y pone de manifiesto el momento arbitrario, violento que rigidifica un texto en un orden simbólico.

Por ello, y pese a vincularse en su origen con un Autor-Padre, la literatura será aquello que, vindicando la impropiedad, desarticule esa estructura misma de la paternidad, y el consiguiente esquema androcentrado de la filiación. La literatura, así, revela que el lenguaje funciona como desapropiación, como descontextualización, como errancia y diferencia del signo. La literatura rechaza su filiación, es siempre un texto huérfano, bastardo, parásito, inmundo, mendigo. Pero esa pérdida de la casa y de lo propio no es una falta o un impedimento para comprender el lenguaje; antes bien, es la forma misma en que la máquina del lenguaje funciona. Por ello mismo, cualquier texto puede devenir literario, convencionalizarse como "literatura": basta con que este pueda, radicalmente, dirigirse ("s'adresser"), marcharse, constituirse como llamada: desde que el texto es "chose publique et publiable" (Derrida, I999: I90), hay literatura, o la posibilidad de devenir-literario. La literatura es, así, una filiación imposible, una suerte de emancipación persistente del texto de todas sus restricciones, una liberación de todos los sentidos que este es capaz de albergar. La literatura, en fin, es el espacio del hijo irreconocible, 
trae consigo siempre un hijo bastardo, un significado impropio, ilegítimo o indeseado. Gracias a la ley, el lenguaje puede tener todos los hijos que quiera, y también los que no quiere. El secreto de la literatura consiste pues en una distorsión de la filiación y de la genealogía como productividad de la palabra.

En síntesis, la literatura nació por derecho y gracias a la ley del Padre-Autor, y solo vive a costa de pervertir esta ley. Su ley consiste en deshacer la ley gracias a la ley. Si hay literatura, ha de ser literatura de ley. Lo que en adelante cabe preguntarse es con qué fuerza subvierte la literatura el vínculo entre texto y violencia, el esquema general de la ley.

\section{La oportunidad de la impureza. Performatividad y literatura}

En la entrevista "Esa extraña institución llamada literatura" (Derrida, 20I7a; Derrida \& Attridge, 2009), Derrida subraya la importancia de este desvío y de esta traición que, haciéndola bastarda o huérfana, constituyen todo lo que la literatura puede tener de propio. "La impureza es la oportunidad", señala Derrida a propósito de esta institución (ibíd., I45). Es en ese decir de más que amenaza con extraviar el sentido de un texto donde la literatura alcanza su vocación política. Son el accidente, lo imprevisto y lo contingente, lo que puede traer esa interrupción y revocación de un orden que acostumbra a llamarse acontecimiento. Si es así, la literatura no será tanto un espacio de compromiso o de acción, sino de pasión; no nos permitirá hacer cosas, sino que nos transformará, nos hará padecer. En esa experiencia de pasión y de vulnerabilidad que trae un texto literario, reside una fuerza de ruptura que nada tiene que ver con el poder, una performatividad que viene a holgar y a desarmar, para traer lo inesperado y lo imposible.

¿Cuál habría de ser la dimensión performativa de la literatura? ¿Cómo pensar su fuerza, que es la fuerza de la equivocidad, del titubeo, de todo aquel decir que no dice nada y que es casi habladuría? Desde su intercambio con Austin y Searle a tal propósito, el vocabulario y la reflexión sobre la performatividad irán calando en el pensamiento de Derrida, hasta permitirle configurar en los noventa un pensamiento del acontecimiento desde el performativo, como observa con lucidez Manrique (2012), y un abordaje de la institución literaria desde la performatividad. Por ello, cabe revisar esta trayectoria para comprender cuál es la fuerza de la literatura.

Desde que Derrida iniciara su debate con los filósofos de Oxford, vastamente cartografiado por investigadores como Didderen (2006: 6 y ss.) o 
Raffel (20II: 277), la posición de sus interlocutores críticos cuenta con un marcado afán de contener o reducir esta impureza en la que Derrida hallará toda la potencia de la literatura. Es un afán de control y normativización de la fuerza del lenguaje lo que, ya desde Austin, constituye la estrategia principal para pensar el funcionamiento del performativo: en ello se revela un presupuesto que Derrida se aprestará a cuestionar: la pureza y el éxito de un acto de habla descansa en la univocidad y la unidad de efecto del lenguaje. Con Austin, se trataría de purgar todos los desvíos y equívocos para que, cuando se hagan cosas con palabras, se haga siempre una cosa, one at a time. Esta estrategia, que no investiga tanto cómo funciona el vínculo entre texto y fuerza, sino cómo debería funcionar para construir eventos comunicativos unívocos, es observable también en autores como Searle o Habermas, quien prescribe una teleología de la acción para garantizar el éxito del performativo (cf. I999: 375-376). El texto literario resulta escandaloso y amenazante para el desarrollo de acciones comunicativas y la institución de órdenes jurídico-políticos asentados en ella, en tanto que la estabilidad de su decir nunca puede asegurarse ${ }^{\mathrm{I}}$.

De este modo, la crítica mayor que Derrida dirige a Austin y Searle pasa, a nuestro parecer, por vindicar que la posibilidad del error, el fracaso o el desvío es una posibilidad estructural del signo como marca iterable, y que por tanto no se trata de purgarla o controlarla por medio del contexto $u$ otras convenciones, sino de pensarla como constitutiva de un acto de habla: en todo acto de habla hay un risk of failure, por invocar la terminología de Austin (I962: 20 y ss.), un efecto comunicativo suplementario y no deseado que pone en cuestión que haya un destino correcto o un único éxito de la marca. De ahí que la literatura, que para Austin era una cuestión no-ordinaria, secundaria y parásita en la teoría de los actos de habla (cf. I962: 2I-22), sea para Derrida el modo general en que funciona el lenguaje cuando se atiende a su condición de cita. De ahí la importancia del parásito, como el suplemento, para Derrida, y de ahí el acento literario en la propuesta derridiana del performativo al vindicar la impureza y la bastardía. Lejos de ser un caso aislado y secundario, la literatura vendría a definir la dinámica general de los actos de habla en su torcimiento esencial: hay un desvío o una indirección que hacen del performativo un "perverformativo", al decir de La carte postale (20I4, I42). Lo que Derrida concibe como "iterabilidad" será entendido, en el marco de este de-

\footnotetext{
${ }^{I}$ Recientemente, autores como Graff-Zivin (2020) o Jacques Lezra (20I7), en línea con la propuesta de Derrida, han tratado de pensar esta fecundidad del error, el accidente y el defecto para articular una política de la literatura.
} 
bate, como una pervertibilidad estructural de la fuerza de las palabras. Por lo que destaca el suplemento que pervierte la performatividad pura no es tanto, en suma, por su carácter constitutivo o productivo, sino al contrario, por su dimensión destituyente. El desvío del performativo interrumpe, depone o cortocircuita los procesos de institución de espacios simbólicos, sea una escena comunicativa, una escena de lectura o un espacio político. Todo mensaje, en fin, marcha, pues, asediado por espectros, por acólitos que le acompañan: es una posibilidad estructural para un mensaje errar y vagar, y tal cosa celebra la literatura: la fiesta del significante, el lenguaje de vacaciones, el texto más allá del principio de productividad.

Así, estas reflexiones iniciales se entrelazan con las cuestiones a propósito de la soberanía que en textos como Voyous (2003b), L'Université sans condition (200I) o États de l'âme (2000) se exponen, especialmente cuando la instancia soberana se concibe como un «autoperformativo» (cf. Senatore, 2013: I9), una performatividad pura que dice lo que hace y hace lo que dice, que produciría inmediatamente y sin resto una positividad, una identidad perfecta. La Palabra plena, el absoluto sentido y el poder soberano van ligados en un mismo esquema onto-teológico, y es esa la primera lección que el enfoque político del performativo nos permite entender. En este sentido, las propuestas de Austin, Searle o Habermas, explicando los modos en que el texto debe articular la fuerza que vehicula para garantizar una constitución exitosa de un marco simbólico no dejan de someter la potencia diseminante de un texto a los juegos de poder en los que este se ve involucrado. Eliminando la impureza, pierden también la oportunidad de la literatura para hacer venir una alteridad. De ahí, pues, la importancia de pensar, como Derrida trata de hacer en los textos mentados, un "más allá del principio de poder", la importancia de si

peut-on penser cette chose apparemment impossible, mais autrement impossible, à savoir un au-delà de la pulsion de mort ou de maîtrise souveraine, donc l'au-delà d'une cruauté, un au-delà qui n'aurait rien à voir ni avec les pulsions ni avec les principes ? (2000: I4).

Pensar este más allá del principio de poder permitiría valorar una performatividad crítica con el principio de soberanía y subvertir el esquema de productividad a que los filósofos de Oxford reducían un texto. Supone valorar si la fuerza de la literatura puede constituir algo así como una resistencia, al mostrarse irreductible a un mensaje, un decir o una acción comunicativa única. Así, este afán de pensar una fuerza más allá del poder pasa por "disociar la «soberanía» (siempre en principio indivisible) y la «incondicionalidad»" 
(2003b: I3). La cuestión de la democracia, como la cuestión de la literatura, va a radicar en si esto es posible, o en tratar de hacer venir esto que es imposible.

Es en este punto donde la posibilidad estructural del error como desvío performativo constitutivo adopta a nuestro parecer otros términos, y es el recurso para pensar la apertura de la democracia y la venida del otro como acontecimiento imposible, y por tanto la importancia de una cierta "pasividad", de la hospitalidad como "dejar pasar". Se ha de pensar, explica Derrida en Voyous,

à la fois l'imprévisibilité d'un événement nécessairement sans horizon, la venue singulière de l'autre, et par conséquent une force faible. Cette force vulnérable, cette force sans pouvoir expose inconditionnellement à (ce) qui vient et qui vient l'affecter. La venue de cet événement excède la condition de maîtrise et l'autorité conventionnelle de ce qu'on appelle le "performatif". Elle déborde donc aussi, sans en contester une certaine pertinence, l'utile distinction entre "constatif" et "performatif" (2003b: I4).

Esta cuestión se retoma en États d'âme para pensar un "hiato absoluto", una "heterogeneidad" tanto para el régimen constativo como para el performativo, que se han revelado como dos formas del principio de poder. Este hiato absoluto forma parte de lo que Derrida llama "el orden de lo imposible" (2000: 86), un registro de la experiencia inconmensurable con el orden de lo posible. Este hiato es resultado de la venida y el obrar de una alteridad que marca aquí una "coupure absolue" (ídem.), y hace del sujeto una pasividad, hace cosas con él, lo desarma y le hace padecer. Lo imposible, apunta Derrida , "excède et met toujours en déroute, parfois cruellement, ce que l'économie d'un acte performative est censée produire souverainement" (2000: 39-40). Derrida denomina "secreto" a esta venida del otro que excede y desvía la economía del sentido y de la fuerza performativa. De ahí que, siempre en États, señale la importancia de pensar el secreto en tanto que «delimita la autoridad misma del poder» (2000: 60). Y así, en el seminario Répondre du secret (I99I-92, S9: 5), se nos explica que toda promesa es promesa de un secreto -y, por ello, un perjurio (cf. Derrida 20I7b)-: no podemos controlar todo lo que trae el lenguaje, él mismo está siempre fuera de sí mismo. Por ende, la literatura, como espacio de alteridad, "inscribe el secreto indestructible en el corazón de la estructura performativa” (I99I-92, ibíd.).

Entendemos, y eso es lo que aquí se querría defender, que todo este esfuerzo por pensar un más allá de la soberanía, así como el esfuerzo temprano de Derrida por pensar una alteridad irreductible en la teoría de los actos de habla, son un modo de entender cómo opera la fuerza de la literatura y cuál es 
su relevancia como artefacto político. El performativo perverso de la literatura constituye esa fuerza débil, difícilmente reducible tanto al constativo como al performativo, que proviene del otro y que cortocircuita la legitimidad y la integridad de un espacio simbólico constituido, a la vez que lo hace posible. La literatura es ese desvío estructural del acto de habla, eso que viene en nuestras palabras sin que sepamos lo que es ni qué efectos va a producir. La literatura, en fin, vindica una suerte de performatividad pasiva, una pasión del habla y un padecimiento de la fuerza incontrolable de los textos. La literatura interrumpe y paraliza, dice que no hay nada que decir: da cuenta de la equivocidad estructural del lenguaje como escritura, y por tanto, también, de la convencionalidad y arbitrariedad de toda performatividad que se instituya como pura y definitiva, soberana. Vinculada al parásito, al bastardo y al huérfano, la literatura está más próxima del grito y de la escritura que de la palabra; es más afín a la risa y al llanto que al verbo. Es ese significante imprevisto, cuerpo sonoro, que perturba toda la economía de la comunicación al encarnar una falta que no se puede colmar, o un resto que no se puede purgar.

\section{El performativo Bartleby}

En su texto sobre el personaje de Melville, Deleuze hacía una observación similar a la que aquí hace Derrida sobre ese performativo débil que no participa del principio de soberanía, sino que lo quebranta. La gloriosa fórmula bartlebiana tampoco se reduce, según Deleuze, ni al orden del constativo ni al del performativo, sino que su agramaticalidad "destroza" "este doble sistema de referencias" (Deleuze, 200I: II7). De modo que el "I would prefer not to" de Bartleby sería similar a ese "Pardon de ne pas vouloir dire" en que Derrida deposita tanto la paradójica textura de la literatura como la ironía de Abraham (Gen 22), quien, requerido por Yahvé a guardar un secreto sin objeto ni contenido, podría hablar cuanto quisiera sin poder jamás revelarlo. Si Abraham habla una "lengua extraña", como señala Kierkegaard en Temor y temblor (2019: 206), es porque el lenguaje del monte Moriah alcanza una suerte de prolijidad estructural, en la que todas las palabras vendrían a decir que, en el fondo, no hay nada que decir. El Bartleby de Deleuze inventa también "una lengua extranjera que discurre por debajo del inglés" (20II: II5) al negarse a producir sentido sin dejar de hablar por ello. Como la literatura, la lengua que invoca la fórmula de Bartleby consiste en hablar de más, en "arrastrar todo el lenguaje", dirá Deleuze, "en hacerlo huir, en llevarlo a su propio límite [...]” (ídem). 
La valoración que hace Derrida sobre Bartleby en su seminario inédito Répondre - $d u$ secret es muy afín a la deleuziana, y permite comprender con mayor claridad todo lo que la fuerza débil de la literatura puede no hacer. Mostrando su acuerdo con Deleuze (I99I-I992, S2: I3), Derrida observará que Bartleby evidencia un sentido en falta que es estructural del espacio literario, y que arruina con ello toda la operatividad y la productividad vinculada al lenguaje. Con Bartleby, el lenguaje está en huelga o de vacaciones, no tiene tesis, no ofrece contenido positivo alguno: el lenguaje se tumba, como escritura, en la horizontalidad del escritorio, y es esa horizontalidad, huelga o vacancia, lo que hace que el texto literario resista a cualquier uso, a cualquier decir y a cualquier poder:

[Bartleby] dit [...] cette absence de sens, ce non-secret qui est comme la loi (c'est un texte de loi et un texte sur la loi) à l'œuvre dans la production du secret. ["Bartleby, the scrivener"] C'est un texte dans lequel la littérature se met en scène comme littérature et avec elle tout ce qui la rend possible et tout ce qu'elle rend possible (I99I-I992, S2: I3).

Todo lo que la literatura puede se vuelve explícito en la historia de este escribiente que no puede, o mejor, que puede no. La fuerza débil se articula en Bartleby a través de pequeñas aporías, como un decir sin decir, o una "respuesta sin respuesta" (I99I-I992, S2: 4). El decir de Bartleby se mantiene extraño, guarda una alteridad no asimilable a la economía comunicativa, permanece como una interrogación abierta, una espera suspendida que hace que el secreto de la literatura "se manifieste como tal" (ídem). La fuerza de este performativo es una resistencia mínima, un gesto de disidencia que, sin poder nada por sí solo, todo lo aguanta, a nada se reduce. Que ese no-enunciado sea ya un enunciado da cuenta de esa prolijidad estructural de la literatura, de su resistencia a operar, de esa fuerza vulnerable que da cuenta de una apertura y de un porvenir del texto que ninguna teoría ni comentario crítico pueden saturar, ni suturar. Esa grieta o ese resto, en que el lenguaje huelga y vaga, es la potencia de destitución de la literatura, de esa gran huelga literaria que nunca da un texto por agotado, que permite a los textos descansar y alcanzar un gesto sabático en que desidentificarse y, una vez más, cada vez única, dejar de ser sí mismos. Es así que Derrida observará, en su entrevista con Attridge, que la performatividad literaria es "una performatividad crítica o incluso una performatividad en crisis" (20I7a: I22-I23), y tiene lugar siempre no como un contenido, sino como "experiencia performativa", recuerda Derrida en Pasiones (20II: I4). 
Con esta performatividad en crisis, que Derrida califica también como "fuerza de ruina" (Derrida \& Attridge, 20I7a: 132), como una fuerza "salvaje" (136), o como un "levantamiento de la represión" (I34-I35), Derrida está reconociendo en la propia literatura, y no en ninguna crítica, método de investigación o comentario, una dinámica política de subversión y disidencia. Institución extraña, fuerza de ruina, artefacto gozoso y salvaje, la literatura es un espacio para la diferencia, y articula una política de la fuerza diferencial, de la desidentificación, huelga o vacancia de los sexo-textos.

\section{Gritos, insultos y quejas. Después de la performatividad en crisis}

¿Cómo pensar una política en que el exceso y el error, lo otro del sentido, el poder y la comunicación directa, son constitutivos? Si bien Gasché señaló que puede hablarse de un performative turn (I999: 256) de la deconstrucción derridiana, como recuerda también Jerade (2020: I53), ¿cómo se concreta esto en términos políticos, habida cuenta de que la performatividad, en Derrida, es literaria, esto es, parasitaria e indecidible? La pertinencia de la pregunta radica, de un lado, en que, como también observa Jerade (ídem), los estudios recientes no han ahondado sobre el carácter político que Derrida imprime a la performatividad, un carácter político que se concretaría, como ha observado Manrique (20I2: 308), en un desplazamiento de la conceptualización de la estructura en términos de iterabilidad en los textos de los setenta hacia la articulación de una concepción de justicia como un exceso performativo del momento singular de la decisión en textos de los noventa como Force de loi (I994). De otro lado, si el error y la transgresión son la clave del funcionamiento del performativo en Derrida, cabría preguntarse por el gesto político estructurado a partir de esta indecidibilidad, articulada como el efecto perlocucionario de esa contrafuerza de la ruina, esa fuerza vulnerable más allá del poder que hemos ensayado más arriba. Sería una política literaria que comenzaría con un "perdón por no querer decir" o con un "I would prefer not to", y que se desplegaría a través de todos esos performativos bastardos, pervertidos, extraños y marginales en que una fuerza errática multiplica los decires y exhibe ese hiato entre un texto y su sentido que la institución literaria no deja de celebrar.

¿Cuáles son, pues, los performativos Bartleby, los que celebran esa gran huelga de sentido que es la literatura? Si bien la teoría queer de los años noventa analizó desde la speech act theory los procesos de interpelación del insulto, 
lo que llevó a Eve Sedgwick a hablar de "deformativo" (I993: 4) y a Judith Butler a pensar una ineficacia estructural del performativo que hacía posible su resignificación (2002:333), recientemente es Hélène Cixous quien ha concebido la literatura en términos cercanos a la performatividad diseminante derridiana al pensarla bajo la figura del grito. En textos como Ayaï! Le cri de la littérature (20I4), Cixous considera el carácter originario de esa ruina, suplemento o contrafuerza que es el grito. La literatura sería, para Cixous, nuestro más largo y prolongado grito, la inscripción de un dolor que permanece aunque el hombre perezca. Con Cixous, de un modo que recuerda a Marguerite Duras, la literatura sería algo así como un grito sin ruido, una institución en que se puede gritar, en que esas formas de lenguaje que no son palabra ni tienen un decir unívoco garantizado pueden tener lugar. Escribe Cixous:

La littérature chante la colère, elle célèbre la divine furie à qui elle doit son existence [...] La littérature c'est pour hurler longtemps, pousser les cris jusqu'à la musique. Le droit à la littérature ou le droit aux cris que la réalité et la communauté nous interdisent (53).

Todo aquello que sofocaba la palabra encuentra asilo en la literatura: el grito y el bramido, la protesta y la queja, en suma, la ilegibilidad del cuerpo, una palabra no humana. La literatura, así, habría de pensarse como ese espacio político que se estructura desde una grieta, desde la interferencia disonante de los gritos. Que en la literatura se pueda gritar, que sea la literatura ese archivo de gritos que nos sobreviven, da cuenta de un espacio simbólico estructuralmente abierto, hospitalario con un decir no-humano, sin palabras, ilógico o aneconómico.

La literatura muestra, en fin, que la ilegibilidad del grito no se opone a la legibilidad de la palabra ni a la armonía del canto; antes bien los recorre, los interfiere, los hace diferir de su pretendida unidad, tiene algo de la irrupción del cuerpo en la legibilidad del texto. De este modo, si la literatura no es tanto el espacio de la palabra cuanto el espacio del grito, quizá comprendamos por qué Derrida vinculó la literatura tan íntimamente con la democracia en Passions (cf. I993a: 65) y otros textos. Esta no es ya, siguiendo a Derrida y Cixous, el sistema del acuerdo o la concordia, el diálogo o la palabra razonada. Antes bien, la democracia es el espacio, como la literatura, que acoge todo aquel alarido que resiste a domeñarse con palabras: y así el tumulto, la jarana y el jaleo, el disturbio y el disenso, el ruido y el ladrido, las voces anónimas, el murmullo de la revuelta. No hay, pues, literatura sin grito. Pas d'écriture sans le cri, pues. La ilegibilidad del grito, en su irrupción, pone en crisis la performatividad 
y la escena de comunicación que esta sostiene, y al quebrarlas y detener su circulación, abre una oportunidad para habitar de otro modo la palabra y cuestionar la violencia que encarna.

Consideremos a continuación las propuestas que ha desarrollado Werner Hamacher en su trabajo sobre la huelga y, más recientemente, Avital Ronell en sus textos sobre la queja. Estas derivas contemporáneas del performativo permiten pensar junto con las anteriores ese régimen de lo imposible, ese secreto inscrito en el performativo en que descansaba la crítica derridiana a la soberanía y, especialmente, su pensamiento de la democracia. En ellos, como en Derrida, es la dimensión literaria de la performatividad lo que le confiere un carácter político disidente. Es también la fuerza imprevista de desvío e interrupción en Hamacher y Ronell el núcleo de su revisión del performativo².

Hamacher trata de pensar, invocando el texto de Benjamin sobre la violencia (2007), la performatividad de la huelga como un aformativo, como una fuerza -débil, vulnerable- que vendría a suspender y destituir el orden estatal, a señalar un vacío u holgura en su constitución, y haría padecer el desvío y la pervertibilidad del performativo. La huelga es, así, una forma de grito, la encarnación de un sujeto imprevisto, al decir de Lonzi (20I8): una voz impropia que irrumpe en la escena política y, reclamando su legitimidad como palabra, interrumpe el orden simbólico al que se adhiere. Así, explica Hamacher (I992: II39):

If one now characterizes law imposition in the terminology of speech-act theory as a performative act [...], it seems reasonable to term the «deposing» of acts of positing and their dialectic, at least provisionally, as an absolute imperformative or afformative political event, as depositive, as political a-thesis. Pure violence does not posit, it «deposes»; it is not performative, but afformative. [...] In all acts, linguistic as well as political (that is, political in the narrow sense), in all acts of legislation as well as jurisprudence, at least an element of this afformative function -this deposing, pure violence- is in effect.

La huelga, como la literatura, era esto: una enmienda a la totalidad de un orden simbólico, una tribulación de un reparto sensible, la emergencia de un cuerpo imprevisible: la aparición casi espectral de un sujeto extraño a

\footnotetext{
${ }^{2}$ Remitimos al excelente trabajo de Senatore 2013 para una historia más detallada de la performatividad después de la deconstrucción. Asimismo, cabe subrayar, junto con Ronell o Hamacher, y los omitidos Butler y Paul de Man, la posición de Agamben, especialmente en textos como El sacramento del lenguaje (20II), donde marca distancias con estas performatividades de la deconstrucción (cf. Agamben, 2011: 84-85).
} 
cualquier dialéctica o desarrollo presuntamente lógico de la historia, hibridando ahora Hamacher y Lonzi. El grito, la protesta, la huelga y, en fin, la literatura, encarnan todo aquello privado de palabra, a todos aquellos abandonados, minorizados o estigmatizados, una estirpe de parásitos que hace valer el desvío y la fuerza de ruptura para desvelar la falta de neutralidad, el carácter contingente y, en suma, toda la violencia que, legitimada como seguridad, bienestar o justicia, se ejerce para sostener, instituir y conservar un Estado. La performatividad de la huelga, pues, no es una forma de positividad (Setzung), sino de Entsetzung: es una deposición. No en vano Derrida señaló en Force de loi que la deconstrucción era una forma de huelga, "dans la mesure où elle prend le droit de contester, et de façon non seulement théorique, les protocoles constitutionnels, la charte même qui régit la lecture dans notre culture et surtout dans l'académie" (I994a: 93). Se trata, en un trabajo de deconstrucción, de holgar las palabras de la filosofía: destapar todos los gritos que acalla el discurso, abordar toda la factura literaria de un artefacto que se quiere sin marca, exento de la violencia de la inscripción. Es propósito de un trabajo deconstructivo señalar la porosidad de la frontera entre filosofía y literatura, entre la palabra y la escritura, entre la palabra y el grito. Por ello la huelga, en el texto y en la calle, es una fuerza literaria 3 .

Por último, Avital Ronell ha tratado de pensar esta performatividad literaria a partir de la queja. En sus términos, la queja sería la forma eminente de recibir y padecer en las palabras una vulneración, y de hacer que la alteridad resuene en el discurso como inconformidad, incomodidad o dolor. La queja libera una performatividad de disenso manifiesto que desata la energía de la protesta, el grito como rebelión y deposición. La queja levanta la carne, es la carne levantándose. Siendo otra forma, pues, de aformativo o perverformativo, la queja vendría a poner en obra una suspensión y un disenso en lugar de promover la conservación o consolidación de un orden político, sea institucional o subjetivo. Consistiría en liberar una fuerza que en un estado normativo tendería a estar sofocado, silenciado, neutralizado en favor de la productividad. Una queja, así, es un cuerpo que acontece, una pasividad que se hace marca.

\footnotetext{
${ }^{3}$ Muchas de estas consideraciones, aunque provenientes de otro lugar, rimarían con los desarrollos que Butler ha expuesto en The Force of Nonviolence (2020). Asimismo, para un análisis más detallado del pensamiento de Hamacher con relación a Benjamin y Derrida, véase Campos, 2020.
} 
La queja es, pues, ya no un speech act, sino una "performatividad pasiva" (cf. Phillips, 20I3), una speech passion, la pasión del habla por excelencia, en que el lenguaje está sometido a una instancia otra, ilegible, que arruina la economía significante de la comunicación. Proclama Ronell:

I want to raise myself to the dignity of the unsounded complaint. It would be more comfortable to pull back, stop howling, go soft and compliant. [...] I would say that each work, according to scales of very unique deliberation and consequence, with distinct backdrop and sound system, registers a complaint (Ronell, 20I7: 237-238).

De este modo, Ronell piensa la relación entre fuerza y lenguaje como una hetero-performatividad, como la fuerza de una alteridad que excita y hace hablar al lenguaje, desplegando una interrupción y una resistencia al cierre o la constitución de cualquier orden simbólico. Con la queja, Ronell piensa ese suplemento de fuerza, originario e incalculable, que desacoplaba el lenguaje del régimen del significado y hacía de él un hablar prolijo y excesivo. Al hacer del lenguaje un espacio de exceso y pasión del habla en que tiene lugar una resistencia, Ronell continúa los esfuerzos derridianos por pensar una fuerza más allá del poder y prolonga su estrategia de hallar, en la afirmación de una negatividad, el momento genuinamente democrático de una política de la literatura. En la queja, pues, resuenan el grito, la huelga, la equivocidad, lo ilegible, la pasión, la literatura, lo otro, el cuerpo, el acontecimiento; en fin, la democracia, lo imposible. Observa Ronell, así, que la queja es

comme un appel que vous recevez par erreur, que vous n'avez pas sollicité, dont personne n'est à l'origine [...] La plainte se heurte à sa propre réserve d'indicibles, conformément à la poésie la plus sublime qui trouve la précision dans le bégaiement. Ces soupirs linguistiques, ces gémissements, autant de signes d'un sens en jachère et d'une tension exacerbée, ponctuent un lieu où l'on ne peut plus rien dire, où l'on expire [...] (2019: 38).

Ronell piensa la queja como una dinámica general, como si todo lenguaje estuviera instalado en un proceso de devenir-queja o devenir palabra del otro; como si el lenguaje, fibromiálgico, estuviera siempre a punto de estallar en un griterío ensordecedor. Si con Hamacher la pervertibilidad del performativo se registraba como aformativo, y la huelga era una versión del performativo Bartleby, con Ronell la hospitalidad de la alteridad se concibe como pasión incontinente del habla. Todo speech act es un speech ache, todo acto de habla es un dolor del habla, diríamos con Ronell. "La plainte", sentencia Ronell, "nous 
a ouvert la voie de la disjointure", "offre une image de l'homme face au déclin de la souveraineté” (2019: 44, 49).

En suma, las distintas derivas contemporáneas del performativo aquí expuestas, del insulto a la queja, hunden sus raíces en las consideraciones con que Derrida concibió la performatividad en crisis de la literatura. El grito, la queja, el aformativo o el deformativo, perverformativos todos ellos, celebran una gran huelga literaria, son esa respuesta sin respuesta, «perdón por no querer decir» o «I would prefer not to», con que la literatura se atribuía el derecho en principio de decirlo todo y no decirlo todo, ese paradójico derecho al secreto y a la diferencia que solo las instituciones democráticas compartían con ella. Aquí es la pasión, destitución, la desistencia y la inoperancia del sentido, en suma, las oportunidades para el acontecimiento.

\section{Huelga decir (notas conclusivas)}

En conclusión, Derrida concibe la literatura como una institución en la que huelga decir. El texto está encamado, hace la huelga o se va de vacaciones, despliega ese afán de alteración en el que consiste su mecanismo y que Derrida denominó como iterabilidad. En esta estructura misma de la textualidad como iterabilidad que el espacio literario permite aprehender, contiguamente con los procesos de institución de sentido, actos de habla, identidades u órdenes simbólicos que habitualmente sostiene la fuerza productiva del performativo, hay siempre contrafuerzas, fuerzas débiles provenientes de esta alterabilidad que revocan y levantan las represiones, las distinciones y las tesis que arman un texto, y así permiten una experiencia a-tética de la tesis, un momento de jouissance desatada en que el texto se vuelve otro. Esta fuerza de ruptura o de ruina da testimonio de la pervertibilidad estructural del texto, y es la oportunidad para destituir todo lo que un texto estaba diciendo, interrumpiendo así la economía política del signo que sostenía. Con todo ello, la dimensión política de la literatura consiste en una afirmación de la negatividad, en vindicar una prolijidad estructural del texto que no se reduce ni se economiza como un mensaje o una comunicación. Esa es la holgura, la huelga, la vacancia o las vacaciones de un texto literario, y esa es, también, la potencia política de la literatura. La literatura, tal y como Derrida la concibe, pone en crisis la performatividad, desarrolla una performatividad crítica que, lejos de establecer un vínculo duradero entre la fuerza y la palabra, lo desajusta y lo multiplica: es una performatividad bastarda, prolija, proliferante. 
Con ello, la literatura no dispone, propiamente, una capacidad productiva o efectiva para, constituyendo un discurso, producir una posición teórica; tampoco se resuelve plenamente en un dispositivo ideológico ni genera pautas de acción en quien lee o escribe. Antes bien, destituye, revoca y suspende todas las formas de la productividad de un discurso, para colocar a quien lee o a quien escribe en el centro del desconcierto: ante un secreto, un sentido en falta, la aporía, una respuesta sin respuesta. En suma, una indecidibilidad que interrumpe los cursos de acción y que impele a decidir, a cuestionar, a reinventar un texto. Por ello, la literatura no requiere sabotaje o deconstrucción, sino que en cuanto institución funciona deshaciéndose, desintegrándose, deviniendo ilegible, disidente: la escritura llega deconstruyéndose. En esta obstinación radica, en fin, la mayor desesperación y la más alta alegría, la frustración y el porvenir, el agotamiento y la oportunidad; el don de todo lo que un texto no nos dará jamás.

\section{Bibliografía}

Agamben, Giorgio. 20II. El sacramento del lenguaje. Arqueología del juramento. Homo sacer II, 3. Valencia: Pre-Textos.

Asensi, Manuel. 20II. Crítica y sabotaje. Barcelona: Anthropos.

Attridge, Derek. 1992. Introduction: Derrida and the Questioning of Literature. En Derrida, Jacques. Acts of literature. Edición de Derek Attridge. Londres: Routledge, pp. I-33.

Austin, John L. Ig62. How to Do Things with Words? Oxford: Oxford University Press. Benjamin, Walter. 2007. Hacia la crítica de la violencia. En Obras II, I. Madrid: Abada, I83-204.

Butler, Judith. 2020. The Force of Nonviolence. An Ethico-Political Bind. Nueva York: Verso.

Butler, Judith. 2002. Acerca del término queer. En Cuerpos que importan. Sobre los límites materiales y discursivos del "sexo". Barcelona: Paidós, 3I3-339.

Campos Salvaterra, Valeria. 2020. Acontecimiento y fuerza diferencial. Benjamin-Hamacher-Derrida. Isegoría. Revista de Filosofía Moral y Política 62: I25-I50.

Cixous, Hélène. 20I3. Ayaï! Le cri de la littérature. París: Galilée.

Deleuze, Gilles. 20II. Bartleby o la fórmula. En Crítica y clínica. Barcelona: Anagrama, I09-I44.

Derrida, Jacques. 20I7a. Esa extraña institución llamada literatura. Una entrevista de Derek Attridge con Jacques Derrida. Boletín 18. Centro de Estudios de Teoría y Crítica Literaria Oct 20I7: II5-I5O.

Derrida Jacques. 20I7b. Le parjure, peut-être ("Brusques sautes de syntaxe"). París: Galilée. 
Derrida Jacques. 20I4. La carte postale. De Socrate à Freud et au-delà. París: Flammarion.

Derrida, Jacques. 20II. Pasiones. Madrid: Amorrortu.

Derrida, Jacques. 2009. Cette étrange institution qu'on appelle littérature. En Dutoit, Thomas \& Romanski, Philippe (eds.) Derrida d’ici, Derrida de là. París: Galilée, $253-293$

Derrida, Jacques. 2006. Dar la muerte. Barcelona: Paidós.

Derrida, Jacques. 2003a. Parages. París: Galilée.

Derrida Jacques. 2003b. Voyous. Deux essais sur la raison. París: Galilée.

Derrida Jacques. 2001. L’Université sans condition. París: Galilée.

Derrida Jacques. 2000. États d'âme de la psychanalyse. L'impossible au-delà d'une souveraine cruauté. París: Galilée.

Derrida Jacques. I999. Donner la mort. París: Galilée.

Derrida Jacques. I994. Force de loi. París: Galilée.

Derrida Jacques. I993. Passions. París: Galilée.

Derrida Jacques. I99I-I992. Séminaire Répondre - du secret, texto inédito consultado en el IMEC con referencia 2I9 DRR 233.I.

Derrida Jacques. I990. Limited Inc. París: Galilée.

Derrida Jacques. I972. Marges de la philosophie. París: Éditions du Minuit.

Derrida, Jacques \& Attridge, Derek. 2009. Cette étrange institution qu'on appelle littérature. En Dutoit, Thomas \& Romanski, Philippe (eds.) Derrida d'ici, Derrida de là. París: Galilée, 253-293.

Didderen, Delphine. 2006. Itérabilité et parasitisme: Essai sur le débat entre Searle et Derrida autour du langage et de l'intentionnalité. Bulletin d'analyse phénoménologique II/4 : 3-I82.

Foucault, Michel. 2009. El pensamiento del afuera. En Entre filosofía y literatura. Obras esenciales I. Barcelona: Paidós, 297-320.

Foucault, Michel. 20I5. La gran extranjera. Para pensar la literatura. Barcelona: Siglo XXI, 36-65.

Gasché, Rodolphe. I999. On Minimal Things: Studies on the Notion of Relation. Stanford: Stanford University Press.

Graff-Zivin, Erin. 2020. Anarchaeologies: Reading as Misreading. Nueva York: Fordham University Press.

Habermas, Jürgen. I999. Teoría de la acción comunicativa. Madrid: Taurus.

Hamacher, Werner. I992. Afformative, Strike. Cardozzo Law Review I3: II33-II57.

Jdey, Adnen (dir.). 2oII. Derrida et la question de l'art. En Déconstructions de l'esthétique, suivi d'un entretien inédit avec Jacques Derrida. París: Éditions Cécile Defaut.

Jerade Dana, Miriam. 2020. Repolitizando las diferencias. Derrida y la teoría de los actos de habla. Isegoría. Revista de Filosofía Moral y Política 62: I5I-I68.

Kierkegaard, S. 2019. Repetición. Temor y Temblor: Escritos 4/1. Madrid: Trotta.

Lezra, Jacques. 20I7. Untranslating Machines: A Genealogy for the Ends of Global Thought. Nueva York: Rowman \& Littlefield.

Lonzi, Carla. 20I8. Escupamos sobre Hegel y otros escritos. Madrid: Traficantes de Sueños. 
Manrique, Carlos Andrés. 20I2. El desplazamiento del concepto derridiano de "performativo": de la iterabilidad de la escritura a la singularidad de la justicia. Natal I9/32: 30I-330.

Phillips, John W. P. 20I3. Passive Performative, en Senatore, Mauro (ed.) Performatives after Deconstruction. Londres: Bloomsbury, I86-205.

Rancière, Jacques. 2007. Politique de la littérature. París: Galilée.

Raffel, Stanley. 20Ir. Understanding Each Other: The Case of the Derrida-Searle Debate. Human Studies 34: 277-92.

Ronell, Avital. 20I9. La plainte (petits griefs entre amis). París: Max Milo Éditions.

Ronell, Avital. 20I7. Ach! The History of a Complaint. En Street, Anna et alii (eds.) Inter Views in Performance Philosophy. Crossings and Conversations. Vancouver: Palgrave Macmillan, 229-246.

Sedgwick, Eve K. I993. Queer Performativity: Henry James's The Art of the Novel, GLQ: A Journal of Lesbian and Gay Studies I/I: I-I6.

Senatore, Mauro. 20I3. Introduction: Positing, the Performative and the Supplement. En Senatore, Mauro (ed.) Performatives after Deconstruction. Londres: Bloomsbury, I-42. 
